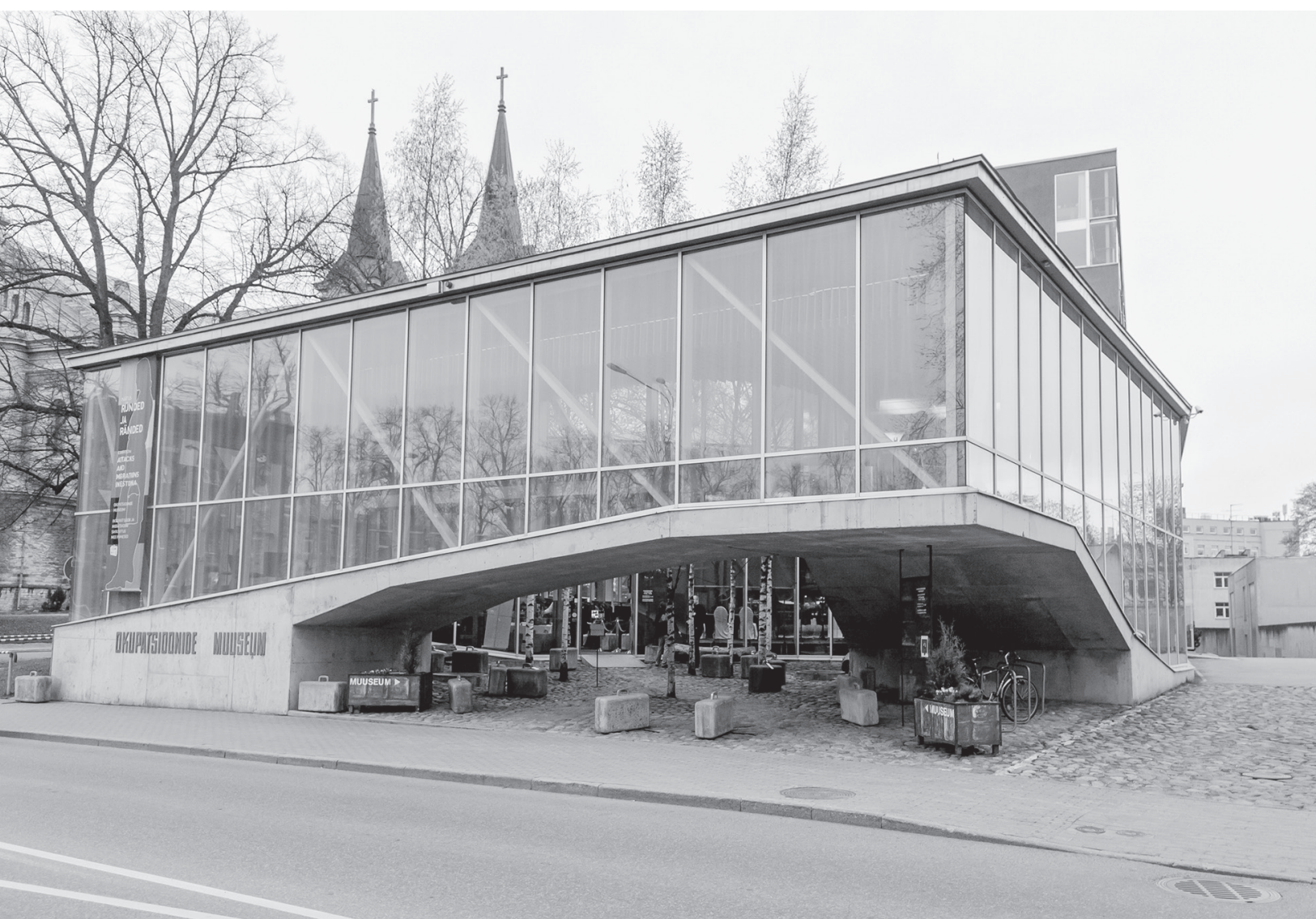




\title{
Okupatsioonide muuseumist Vabamuks: nimetamispoliitika analüüs
}

\author{
Ene Kõresaar, Kirsti Jõesalu
}

See pole ainult üks muuseum, ainult üks väljapanek. See on paik, mis käsitleb meie eksistentsi aluseid. Ja selle tõttu tundub selle nimi ka nagu meie kõigi asi [...].

Selles nimes vihiseb iga piitsahoop, mida meie esivanemad on kogenud, iga veriselt maha surutud ülestõus, iga alandus ja mõnitus. See nimi puurib sügavale meie kollektiivsesse alateadvusesse, ja äratab seal üles ka kohati juba uinunud koletisi. See nimi toksab jõuliselt ka hirme, et kui me nüüd ei räägi, siis ehk me enam ei mõtle. Ja kui me enam ei mõtle, siis ehk me unustame.

Ja kui me unustame... siis mis tagab, et see kõik ei tule uuesti?

Aga suur küsimus on, kuidas on võimalik olla vaba, samas unustamata.

(Rain Kooli 2016)

\section{Sissejuhatus}

Käesolev artikkel keskendub Vabamu nimedebatile laiema eesmärgiga arutleda nõukogude perioodi mäletamise kultuuri muutumisvõimaluste üle tänapäeva Eestis. ${ }^{1}$

17. veebruariks 2016 kutsus Okupatsioonide muuseum oma sõpru ja koostööpartnereid muuseumisse et „rännata üheskoos läbi järgneva paari aasta, mil maja ootab ees nii väline kui sisemine taassünd”. Muuseum kutsus mõtisklema, „kuidas vabadust hoida ja selle eest seista ja mis on uueneva muuseumi peamine väljakutse." ${ }^{2}$ Kohtumisel lubati vastata küsimustele muuseumi tuleviku, uue püsinäituse ja uut projekti vedavate inimeste kohta.

[1] Artikkel on valminud ERA.Net RUS Plus programmi projekti LIVINGMEMORIES ning Haridus- ja Teadusministeeriumi (IUT34-32) toel. Autorid tänavad Merilin Piipuud ja Sander Jürissoni toetava suhtumise ja avatud diskussiooni eest. Eriline tänu kuulub Merilin Piipuule kaasamõtlemise ja kommentaaride eest selle artikli varasemale, ingliskeelsele versioonile.

[2] Okupatsioonide muuseumi e-kiri, 10.02.2016. 
Peaesinejad olid Eesti Vabariigi president Toomas Hendrik Ilves, muuseumi nõukogu liige ja idufirmaettevõtja Sten Tamkivi ning tegevdirektor Merilin Piipuu. Kohtumise esimene osa oli pühendatud koostööle ja ühisrahastamisele: muuseum soovis leida vahendeid uue püsiekspositsiooni ja hoone rekonstrueerimise jaoks. ${ }^{3}$ Neil teemadel arutlenud Ilves ja Tamkivi tõid näiteid nii Ameerika Ühendriikidest kui ka Eestist, rõhutades kodanikualgatuse tähtsust avalikes asjades. Uut nime Vabaduse muuseum - mainis esmakordselt president Ilves. Kavandatavat nimemuutust - Okupatsioonide muuseumist Vabaduse muuseumiks ehk Vabamuks ürituse kutses ei mainitud, kuid just nimemuutus põhjustas laiema arutelu mälust Eesti ühiskonnas.

Lähemalt avas plaanitavat nimemuutust Piipuu, kes toetus oma sõnavõtus president Meri 2003. aastal muuseumi avamise puhul peetud kõnele. ${ }^{4}$ Rõhutades vabaduse väärtust sellise ajaloolise kogemusega ühiskonna puhul nagu Eesti, tutvustas Piipuu keskseid mõisteid muuseumi uuenemisel: okupatsioonile lisanduvad vabadus, vastupanu ja taastumine. Muuseumi uuenemise ajendid jäid üritusel tagaplaanile, rõhutati pigem noorte kui sihtgrupi kaasamist. Kohapeal erilist diskussiooni ei tekkinud, publik esitas vaid mõned küsimused (vt ka Weekes 2017). Nädala jooksul aga algas elav arutelu kavandatava nimemuutuse üle, mis osutas nii nõukogude mineviku mäletamise hetkeseisule kui võimalusele seda mõjutada ja muuta. Pärast ligi pool aastat kestnud debatti ja näituseplaanide täpsustamist läks muuseum kompromissile, otsustades pärast muuseumi renoveerimist ja uue püsinäituse avamist jätkata nime all Okupatsioonide ja vabaduse muuseum Vabamu.

Lähtudes nimetamise poliitika teoreetilisest raamist, keskendutakse käesolevas artiklis nn Vabamu debati põhiteemadele, võtmekõnelejatele ning mälupoliitilisele kontekstile. Esiteks selgitame mõistet okupatsioon Eesti poliitilise identiteedi ning Baltimaade, Venemaa ja Euroopa suhete aspektist. Järgmiseks analüüsime peamisi teemasid, mis kerkisid üles Vabamu nimedebatis. Kes olid selle peamised kriitikud? Millised praeguse mälurežiimi mallid ja millised mälupoliitilised raamistikud ilmnesid? Analüüsitu põhjal arutleme mälu-uurimuslikust vaatepunktist selle üle, miks Vabamu nimemuutus esialgse plaani järgi ei teostunud.

Analüüsi põhiallikaks on ajakirjanduse ja sotsiaalmeedia tekstid. Lisaks meediaanalüüsile intervjueerisime muuseumi tegevdirektorit Merilin Piipuud. Samuti kutsuti meid osa võtma muuseumi nõuandva koja kohtumistest, kus olime pigem kuulajate kui nõuandjate rollis. Lisaks osalesime muuseumi korraldatud üritustel ja külastasime ajutisi näitusi. Osalus, vaatlus ja intervjuud võimaldasid meil lisaks nimedebati arengu dokumenteerimisele avada Vabamu nime taga olevaid kontseptuaalseid eesmärke, mida muuseum esialgu meedias ei selgitanud. Siinses artiklis on meie peatähelepanu nimedebatil ja sellel, mida see ütleb Eesti mälukultuuri kohta, sest uue museoloogia ideestik eraldi teemana debatis üles ei kerkinud.

[3] Muuseumil on ingliskeelne ühisrahastamise lehekülg: http://vabamucampaign.org

[4] Lennart Meri kõne on kättesaadav aadressil http://www.okupatsioon.ee/images/President_Meri_avamiskone.pdf. 


\section{Okupatsioon: nimetamise poliitika}

Eesti Okupatsioonide muuseumi nimemuutuse plaanide avalikustamisele järgnenud reaktsioon näitas, kui oluline on mälumaastikul nimetamise poliitika. Nimed, nagu osutavad Kearns ja Berg (2002), moodustavad osa sümboolsest ja materiaalsest korrast, mis tagab normaalsuse ja legitiimsuse mälupoliitikas. Kohtade nimetamine on tänapäeva ühiskonnas identiteedipoliitika võtmekomponent, „omandisuhete, võimu- ja kontrollitaotluse normeerimise praktika“" (Berg ja Kearns 1996: 99). (Ümber)nimetamise ja poliitiliste sümbolite asendamise kaudu osalevad inimesed poliitilistes aktides, mis annavad sündmustele, objektidele ja kohtadele kas positiivse või negatiivse seose. 20. sajandi Eestis on muuseumide nimesid muudetud poliitiliste režiimide vahetumisel: näiteks Eesti Rahva Muuseum Riiklikuks Etnograafiliseks Muuseumiks (1940), seejärel 1941 tagasi Eesti Rahva Muuseumiks, 1952 ENSV TA Etnograafia Muuseumiks, 1963 Eesti NSV Riiklikuks Etnograafiamuuseumiks ja 1988 taas Eesti Rahva Muuseumiks.

Nimetamine seostub seega ideoloogiliste protsessidega, mis kaasnevad kollektiivse identiteedi loomisega. Ajaloosündmused ja ajaloolised võtmefiguurid saavad igapäevaelu osaks tänavate ja mitmesuguste avalike institutsioonide (nt muuseum) näol. Sel viisil meenutatakse näiteks rahvusgrupi liikmetele nende rolli rahvaste seas ning kinnitatakse järjepidevust. Manipuleerimine keele kui vahendiga, mille abil luua või hävitada identiteedi- ja solidaarsustunnet, on väga vana võte (Brodsky 2001: 420).

Nimed väljendavad kollektiivse mälu korraldust. Palju on uuritud näiteks paikade (tänavate, hoonete, linnade) ümbernimetamist pärast revolutsioonilist ühiskonnamuutust (vrd Vukov 2007; Palonen 2008; Light ja Young 2014). Selline ümbernimetamine on mõeldud institutsionaliseerima uut poliitilist korda ning kujundama igapäevakogemuste tähendusi. Nimed ja nimetamine on osa mälupoliitikast, mis määratleb, mis on ajalooliselt oluline, ja väärib avalikku mäletamist (Alderman 2002). Sel viisil osalevad nimed ja nimetamine poliitilise diskursuse ja identiteedi konstrueerimises.

Okupatsiooni kontseptsioon on olnud nii postkommunistliku Eesti kui ka teiste Balti riikide poliitilise identiteedi tuumaks. Okupatsiooni mõiste on seotud kõigi oluliste elementidega Eesti nõukogudejärgses narratiivis: Teise maailmasõja sündmuste ja Punaarmee rolliga, hinnanguga Nõukogude süsteemile ja selle kokkuvarisemisele ning iseseisvuse taastamisele. Eesti riikluse aluspõhimõte on õigusliku järjepidevuse doktriin, mis vaatleb Eesti riiklust kui taastatud riiklust pärast 50 aastat Nõukogude okupatsiooni ning Eesti annekteerimist 1940. aastal. Selle doktriini kohaselt, mis hakkas kehtima nii juriidilisel, ühiskondlikul kui ka kommemoratiivsel tasandil pärast Nõukogude Liidu kokkuvarisemist (Tamm 2012), võisid Balti riigid küll 1940. aastal lakata eksisteerimast de facto, kuid eksisteerisid endiselt de jure, sest võimuvahetust ei peetud ei Baltimaades ega mujalgi seaduslikuks (Ehin ja Berg 2009: 9). Seega kinnitasid Balti riigid NSV Liidu kokkuvarisemisel, et nad ei loo uusi riike, vaid taastavad oma iseseisvuse (Muižnieks 2011: 13).

Balti riikide mälupoliitikat kommunistliku mineviku suhtes (eristatud ka kui „Balti mudelit“, vt Troebst 2007; Zhurzhenko 2007), iseloomustas Nõukogude režiimi radikaalne eksternaliseerimine välise jõu pealesurutud nähtusena. Kom- 
munikatiivse, kultuurilise ja poliitilise mälu tasandil võrdusid kommunistlikud aastakümned kannatustega Nõukogude režiimi all: aastat 1940 nähti sõjalise okupatsiooni ning jõuga annekteerimisena ning aastat 1944 mitte vabastamise, vaid ühe vägivaldse okupatsioonirežiimi asendumisena teisega. Pärastisi hilissotsialismi aastaid nähti rõhumise ja tagakiusamise jätkumisena, millega kaasnes kasvav hirm eesti rahva pikemaajalise kultuurilise säilimise pärast (Kõresaar 2004; Smith 2008). Ametlikus mälupoliitilises sfääris selline diskursus jätkus, samal ajal kirjeldatakse kommunikatiivses ja kultuurimälus alates 1990. aastate lõpust Nõukogude kogemust märksa ambivalentsemalt (Jõesalu ja Kõresaar 2013).

Nn okupatsiooniparadigma (Zhurzhenko 2007) on ka Eesti/Balti-Vene suhete keskmeks. Eesti ja Venemaa narratiivid on oma rahvusidentiteedi ja kollektiivse mälu põhikontseptsioonides antagonistlikud (Ehin ja Berg 2009: 10). Alates 1992. aastast on Venemaa kasutanud Nõukogude minevikku omaenda rahvuse ülesehitamise projektis, väites, et 1940. aastal Balti riike ei okupeeritud, vaid tegemist oli vabatahtliku inkorporeerumisega ning 1944. aasta tähendas seega vabastamist (Doronenkova 2011). 1990. aastatel olid Balti-Vene suhetes valdavad mitmed vaieldavad teemad, mille seas tõsteti korduvalt üles kommunistliku mineviku nimetamise küsimus. Euroopa Liidu laienemise ning Venemaa võimu ja ambitsioonide kasvades ilmnesid nii vanad kui ka uued pinged, mis väljendusid sümboolses võitluses Nõukogude mineviku pärast (Ehin ja Berg 2009: 5-7; Mälksoo 2009; Zhurzhenko 2007; Onken 2007). Venemaa tajumist ohuna on alates 1990. aastast toitnud pingelised suhted Balti riikide ja Moskva vahel, mida on õhutanud ka Venemaa kaasmaalastepoliitika (Smith 2008). Omalt poolt on Balti riigid kogu aeg Venemaad kritiseerinud demokraatia ja inimõiguste küsimuses ning püüdnud vastastada Venemaa püüdeid esitleda end kui Euroopa vabastajat (Mälksoo 2009).

Pärast värvilisi revolutsioone Gruusias (2003) ja Ukrainas (2004) omandas okupatsiooniparadigma laiemagi geopoliitilise mõõtme. See tähistas nihet antikommunistlike ja Venemaa-vastaste narratiivide suunas. 2006. aastal, inspireerituna muuseumidest Tallinnas ja Riias (avatud 1993), avati ka Tbilisis Gruusia Rahvusmuuseumi osana Nõukogude okupatsiooni muuseum. Umbes aasta hiljem nimetati Kiievis asuva vabaühenduse Memoriaal 2001. aastal avatud püsinäitus „kommunistlikust inkvisitsioonist" Nõukogude okupatsiooni muuseumiks. Pärast nõukogude sümboolika kasutamise keelamist ning selle režiimi kuritegelikkuse eitamise kriminaliseerimist 2015. aastal tehti Kiievi linnavalitsuses plaane Nõukogude okupatsioonile pühendatud muuseumpargi avamiseks (Vaba Euroopa raadio 2015). ${ }^{5}$ Ka Moldova avas 2016. aastal Chisinău Riiklikus Sõjamuuseumis püsinäituse „Nõukogude okupatsioon" (Kaitseministeerium 2016).

Okupatsiooni mõistet puudutav poliitika näitab keelelise määratluse olulisust laiaulatuslikumas võitluses mineviku esitamise pärast (Ashplant, Dawson ja Roper 2004: 54-60). Mingi sündmuse määratlemine ja seeläbi legitimiseerimine mõjutab paratamatult viise, kuidas sündmust mäletatakse ja meeles peetakse.

[5] Kommunismi eksternaliseerimine nn okupatsiooniparadigma järgi pole kollektiivse mälu lahknevuse tõttu Ukrainas siiski samamõõduline kui „Balti mudelis“ (vt Zhurzhenko 2007). 


\section{Okupatsioonide muuseum: memoriaalist dünaamiliseks muuseumiks}

Eesti Okupatsioonide muuseumi asutamise algatas Kistler-Ritso Eesti sihtasutus, mille omakorda rajas eesti pagulane Olga Kistler-Ritso 1998. aastal. Pärast aastaid kestnud akadeemilist uurimistööd ning esemete kogumist püsinäituse rajamiseks ja täiendamiseks ${ }^{6}$ avatigi muuseum 2003. aastal avalikkusele. Esmalt avati muuseum nime all Eesti lähimineviku okupatsioonide muuseum, mis järgnevatel aastatel lühendati Okupatsioonide muuseumiks. ${ }^{7}$ Tähendusrikkalt sai muuseumi esimeseks juhiks endine Nõukogude aja dissident ja poliitvang Heiki Ahonen.

Oma eesmärkidelt ja väljapaneku iseloomult kuulus Okupatsioonide muuseum kultuuriasutuste lainesse, mis rajati alates 1990. aastate algusest Ida-Euroopas pühendatuna kommunistlikule kogemusele (Knigge ja Mählert 2005). Muuseumi püsinäituse eesmärk oli esitada „objektiivne läbilõige elust Eesti ühiskonnas kolme okupatsiooniperioodi vältel“ (ingliskeelne reklaamleht, tsit Kuusi 2008: 106). Püsinäitus oli üles ehitatud Eesti okupatsioonide, rahvusliku vastupanuliikumise ja iseseisvuse taastamise kronoloogia järgi 1940-1991. Minevikku raamistati püsinäitusel valdavalt kui traumanarratiivi, mis keskendus Nõukogude režiimi toime pandud julmustele, mis omakorda toimisid raamistikuna natsistliku okupatsiooni vaatlemisel (Mark 2008; Radonič 2017: 280). Piiratud ruumis oli vaatamiseks välja pandud ka esemeid, mis kujutasid nõukogudeaegset igapäevaelu. Muuseumi avamisest saadik on näitusele olnud vastuolulisi reageeringuid: ühelt poolt väidavad kriitikud, et keskendudes okupatsiooni poliitilisele ajaloole välistas muuseum kaudselt need, kes polnud otseselt Nõukogude repressioonide ohvrid (Velmet 2011; Mark 2008; Kuusi 2008; Ein studentischer Erfahrungsbericht 2005: 198), teised jälle leiavad, et väljapanekud valiti ja esitati viisil, mis võimaldas individuaalset ja emotsionaalset sidet nõukogude minevikuga, sealhulgas nostalgiat (Kuusi 2008; Ein studentischer Erfahrungsbericht 2005: 205).

Okupatsioonide muuseumi eesmärk oli harida ja mälestada, kõnetades seega kolme külastajate gruppi: 1) noori inimesi, kel ei ole Nõukogude režiimi kogemust, 2) põlvkondi, kes elasid okupatsioonid üle, ja 3) väliskülalisi, kel puuduvad eelteadmised Eesti lähiminevikust (Ahonen 2005: 113). Kui vahetult pärast muuseumi avamist võis direktor teatada elavast huvist kõigi kolme grupi seas (Ahonen 2005: 115), siis 2009. aastaks olid külastajateks valdavalt vaid turistid ja kooliõpilased muuseumi lähinaabrusest (Velmet 2011: 199). 2015. aastaks olid vaid 10\% külastajatest (umbes 2000 inimest) kohalikud. ${ }^{8}$ Muuseumi püsiekspositsioon aastast 2003 oli vananenud ega kõnetanud enam külastajaid. Seega oli vaja muuta ekspositsiooni ja leida uuesti oma publik.

Pärast uue tegevdirektori ning uute nõukogu liikmete määramist 2015. aastal võttis muuseum ette kaua kavandatud uuenduskuuri (vt ka Sikk 2012). Muuseum

[6] Kistler-Ritso sihtasutuse organiseeritud akadeemilistest uuringutest Nõukogude okupatsiooni ja annekteerimise kohta, samuti eksponaatide kogumisest avalike kuulutuste ja rohujuuretasandi võrgustike abil vt Ahonen 2005.

[7] Üks muuseumi vahepealsetest nimedest oli Okupatsiooni ja vabadusvõitluse muuseum (Kuusi 2008).

[8] Vestlus Piipuuga 7. jaanuaril 2016. 
seadis eesmärgiks laiaulatuslikud museoloogilised, muuseumihariduslikud ja organisatsioonilised muudatused, et tõmmata ligi nooremat publikut ja laiendada sihtgruppi. Muutustega kaasnes muuseumi ümbermõtestamine minevikku vaatavast asutusest kaasavaks kodanikuühiskonna organisatsiooniks, kes tegeleb ka ühiskondlike teemadega.

Muuseumi muutumist pidi ka kajastama uus nimi: Vabaduse muuseum Vabamu. Reorganiseerimisest teatati avalikult 2016. aasta veebruaris ja uue püsinäituse avamine kavandati 2018. aastasse, tähistamaks Eesti Vabariigi 100. aastapäeva. ${ }^{9}$ Uus väljapanek keskendub vabaduse saavutamisele ja säilitamisele ning kodanikuõigustele Eestis. Nimemuutus pidi tähistama muutust vabaduse ja inimõiguste mõistmisel võrreldes esimese väljapanekuga: kui varasemas väljapanekus mõisteti kodanikuõigusi kollektiivsel tasandil (õigus rahvuslikule enesemääramisele), siis uue väljapaneku kuraatorid rõhutasid inimõigusi ja vabadust. Keskendudes võtmesõnadele okupatsioon, vastupanu, vabadus ja taastumine on kavas eksponeerida järgmisi teemasid: okupatsioonide ajal toime pandud julmused, massiline põgenemine läände 1944. aastal ning elu eesti pagulaskogukondades pärast Teist maailmasõda, samuti igapäevaelu nõukogude ajal, iseseisvuse taassaavutamine ning mitmesugused vabadused. Tulevase näituse peaeesmärk on vahendada minevikku isikulugude kaudu ning rõhutada kodanikujulguse avaldumist okupatsioonide perioodil. Eeskujuna nähti Museum of Tolerance'i ehk Simon Wiesenthali keskmuuseumi Los Angeleses, Anne Franki muuseumi Amsterdamis ja Juudi muuseumi Berliinis. ${ }^{10}$ Muuseumi uus kontseptsioon järgis globaalsemaid mudeleid, lähenemaks minevikule demokraatlike väärtuste kaudu. Nimemuutuse ja tulevase näituse kava osutab põhjalikule muutusele Okupatsioonide muuseumis nii rahvusvaheliste museoloogiliste suundade kui ka mälutöö mõttes.

\section{Vaidlused nimemuutuse üle}

Muuseumi nimemuutmise plaan tekitas ühiskonnas ägedaid vaidlusi (Nõukogude) sõjalise okupatsiooni koha ja tähenduse üle, toonaste kannatuste ja nende mäletamise üle. Vabaduse „paigutamine“ muuseumi (Vabaduse muuseum) tundus inimestele semantilise probleemina. Sellist arvamust väljendasid ka need, kes polnud muuseumi uuendamise suhtes sugugi kriitilised. Eriti sotsiaalmeedias leiutati nimest Vabamu hulk iroonilisi tuletisi.

Muuseumi nime muutmise plaanid elustasid mitmed varasemad, nõukogudejärgses mälutöös aktuaalsed teemad. Poole aasta jooksul, veebruarist augustini 2016, avaldati siinses ajakirjanduses üle 60 loo - arvamuse, uudise ja kommentaari -, millega kaasnes elav diskussioon sotsiaalmeedias (peamiselt märtsis-aprillis 2016).

[9] Artikli avaldamise ajaks oli avamine lükkunud 2019. aastasse, seisuga sügis 2017 on endiselt avatud ka vana püsinäitus.

[10] Vestlustest näituste juhi Sander Jürissoniga 10. mail 2017, intervjuudest Merilin Piipuuga 13.10. ja 8.12.2016, vt ka Tigasson 2016. 


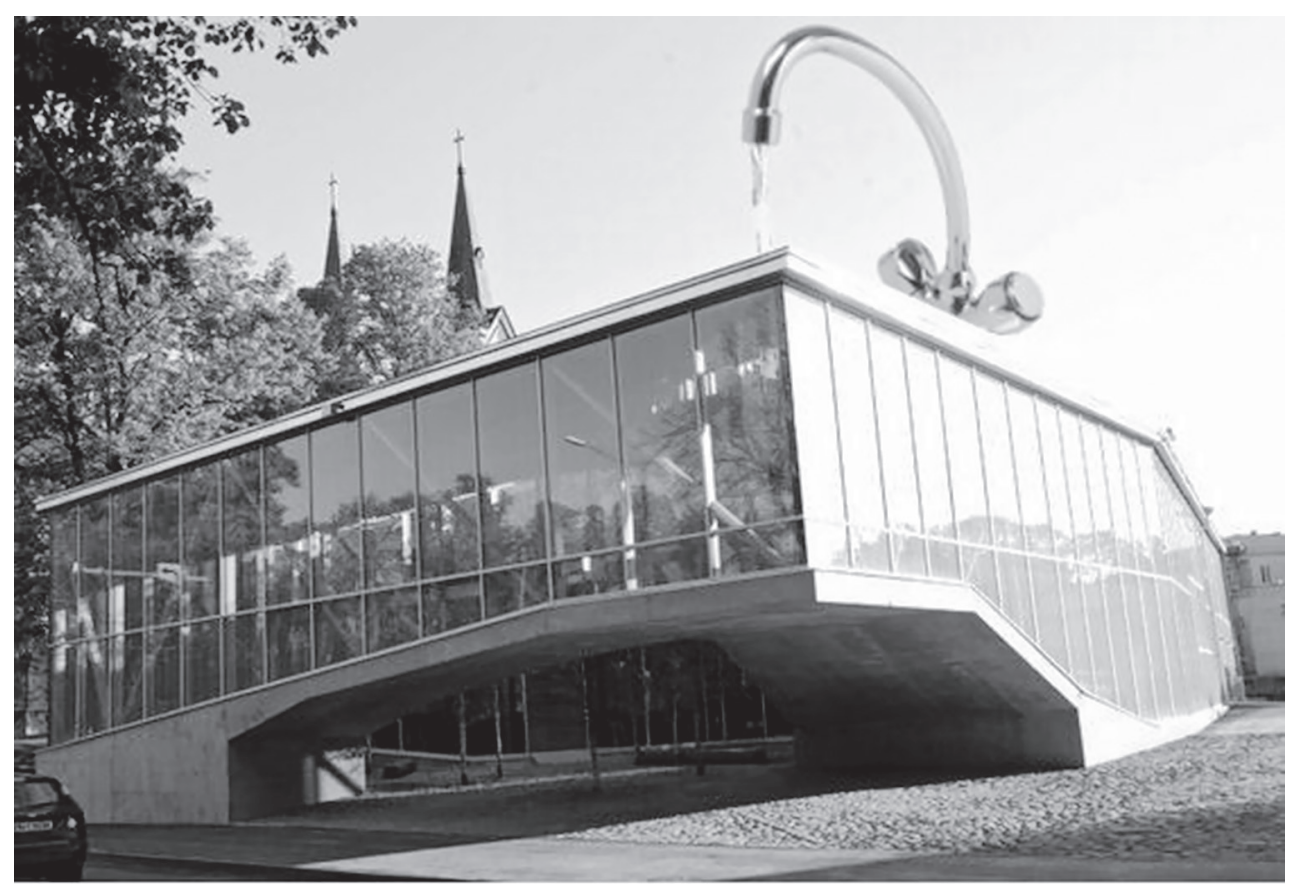

\section{OKUPATSIOONIDE MUUSEUM MUUDETAKSE VALAMUKS}

Foto 2. Vabamu - valamu.

Allikas: Allah Pugatchova

Esimesed ülevaated kirjeldasid muuseumi positsiooni. Kuid 21. veebruaril teatas Enn Tarto avalikult, et on nimemuutuse vastu (Ojakivi 2016). Mari-Ann Kelam väljendas oma muret selle pärast, kuidas uut nime rahvusvaheliselt mõistetakse (Põld 2016a). Oma rahulolematust näitas kohe ka Mart Helme (Einmann 2016). Esimese põhjaliku kriitika avaldas Kanada eestlane Marcus Kolga Eesti Rahvusringhäälingu (ERR) ingliskeelses portaalis (Kolga 2016a). Paar päeva hiljem vastas Kolgale samas portaalis muuseumi tegevdirektor Piipuu (Piipuu 2016a). Järgnevate nädalate vältel ilmus ohtralt arvamusavaldusi ja seisukohavõtte. Oluline hetk debati arengus oli massiküüditamise ohvrite mälestuspäev 25. märtsil 2016: sel päeval väljendasid avalikult arvamust paljud inimesed, sealhulgas Eesti Memento Liidu esindajad.

Diskussioonides jäid kõlama järgnevad arvamused: 1) Memento ja nõukogudeaegsete dissidentide arvamused meediakommentaaridena ja avalike seisukohavõttudena; 2) poliitikute (peamiselt paremkonservatiivsete EKRE ja IRL) seisukohavõtud; ${ }^{11}$ 3) tuntud kultuuritegelaste arvamused (näit Imbi Paju, Jaak

[11] Lisaks EKREle ja IRLile küsiti arvamust ka sotsiaaldemokraatide esindajalt, kes on ühtlasi Eesti kultuuriminister. Indrek Saar võttis neutraalse seisukoha, öeldes et otsustajaks peaks olema muuseum ise, millist nime ja ekspositsiooni kasutada. Teisalt otsustas Kultuuriministeerium uue püsiekspositsiooni toetamise alles augustis 2017, vahetult pärast KGB 
Jõerüüt ja Rein Veidemann); 4) eesti pagulaskogukonna liikmete arvamused; 5) tegevdirektor Merilin Piipuu ja Kistler-Ritso sihtasutuse esinaise Sylvia Thompsoni, sihtasutuse asutaja tütre arvamused, mis kajastasid muuseumi kavatsusi, ja 6) muuseumi algatatud avalik arutelu. ${ }^{12}$ Järgnevatel lehekülgedel vaatleme peamisi nimedebatis esile kerkinud teemasid. Eriti radikaalsetes konservatiivsetes võrgufoorumites seostati Vabamu juhtum migratsioonikriisi ja kooseluseadusega, mida me alljärgnevalt ei käsitle. ${ }^{13}$ Analüüsime siinses artiklis diskussiooni peamisi teemasid nimetamise poliitika ja Eesti 20. sajandi ajaloomälu kontekstis. ${ }^{14}$

\section{Ohvrid ja tunnustamise poliitika}

Väliseestlane Marcus Kolga tõi oma arvamusloos (2016a) välja, et muuseumi nimemuutmise ja uue kontseptsiooni tutvustamise ürituselt 17. veebruaril 2016 puudusid poodiumidiskussioonil osalejate seast Nõukogude režiimi ohvrite põlvkonna esindajad. Nagu näitas järgnenud arutelu, tundsid ka need, kes olid repressioone ja tagakiusamist Nõukogude režiimi ajal otseselt kogenud, end muuseumi algatatud muutusteprotsessist kõrvale jäetuna. 25. märtsi küüditamise mälestamise aastapäeval pidas represseeritute organisatsiooni Eesti Memento Liidu esimees Leo Õispuu muuseumis emotsionaalse kõne, mida kajastati meedias ning väitis, et represseeritud on muuseumi muutumisplaanidest kõrvale jäetud (Haravee 2016; Rohemäe 2016; Pöördumine 2016). Õispuu nõudis oma organisatsioonile Nõukogude okupatsiooni teema sümboolset omandiõigust: „Represseeritud peavad seda [okupatsiooni] oma teemaks - sellega peab arvestama!“ Tema seisukohalt võrdus nimemuutus muuseumi ilmajätmisega 20. sajandi julmuste mälestaja funktsioonist. See tähendaks „okupatsiooni nullimist", väitis ta mälestuspäeval (Õispuu 2016). Tuntud Nõukogude perioodi teisitimõtlejad (Enn Tarto ja Lagle Parek) väljendasid samuti oma hukkamõistu (Ojakivi 2016; Põld 2016a; Põld 2016b).

Nagu vaidlused nimemuutuse üle näitasid, pidasid represseeritud Okupatsioonide muuseumi oma sümbolpaigaks (vt ka Sepp 2016). Okupatsiooni kadumine muuseumi nimest aktualiseeris represseeritute jaoks nende kogemuse tunnusta-

muuseumi avamist. Muuseumi algatatud diskussioonis kutsuti osalema Reformierakonna liikmed Yoko Alender ja Eerik-Niiles Kross.

[12] Muuseum algatas koostöös ERRi veebiportaaliga arutelusarja „Kuidas mäletada? Eesti rahva lugu okupatsioonist vabaduseni." Teemadeks olid: 1. Okupatsioonid: lahati küsimust, kuidas erinevad eestimaalaste põlvkonnad okupatsioonidest kõnelevad ja seda ajaperioodi enda jaoks lahti mõtestavad (osavõtjad David Vseviov, Neeme Raud, Yoko Alender ja Kristin Parts, 11. aprillil 2016), 2. Vastupanu (Toomas Hiio, Helen Tammemäe, Martin Andreller ja Eerik-Niiles Kross, 4. mail), 3. Taastumine (Mall Hellam, Ville Jehe ja Aro Velmet, 3. juunil). Osavõtt diskussioonidest toimus kutsetega, arutelusid juhtis ERRi ajakirjanik Rain Kooli.

[13] Nimevahetus seostati kooseluseaduse ümber käiva debatiga eriti intensiivselt alates aprillis avatud Jaanus Samma näitusega „NSFV. Esimehe lugu“, vt Taavetti (ilmumas).

[14] Analüüsi keskmes on debati arenemine Eesti meedias (hargmaises mõttes). Eesti venekeelses meedias ilmus kogu diskussiooni vältel vaid mõni rida, põhiliselt jooksvate uudiste kokkuvõtetena. Arutelu jäämine valdavalt eestikeelse kogukonna piiridesse viis 2017. aasta suvel tulemuseni, et $68 \%$ venekeelsetest küsitletutest ei osanud vastata küsimusele „Kas toetate Okupatsioonide muuseumi nimetamist Vabamuks?“ (Uuring 2016). 
mise poliitika keerukuse 1980. aastate lõpust alates (vt ka Anepaio 2002). Lisaks käis sellal, kui muuseum avalikustas idee nimetada end Vabamuks, veel teinegi debatt, mille keskmes oli kommunismiohvrite memoriaali rajamine Tallinna. Memento leidis, et ka selles vaidluses nõrgendatakse nende positsiooni. Memoriaali kavandamine oli saanud alguse aastaid tagasi, läbinud mitu ettevalmistavat faasi ning nüüd oli vaja saavutada kokkulepe sobiva koha leidmiseks. Kuni memoriaali valmimiseni pidi Okupatsioonide muuseum represseeritute jaoks sümboolselt selle kohta täitma. Õispuu leidis, et „seni, kuni meil on okupatsioonidele pühendatud just see üks muuseum, peab ka praegune nimi alles jääma“ (Haravee 2016).

Päev enne 25. märtsi mälestuspäeva kuulutas RKAS välja ideekonkursi Maarjamäele püstitatava kommunismiohvrite memoriaali ja ohvitseride monumendi jaoks, konkurss seoti ka Eesti Vabariigi 100. aastapäeva tähistamisega. Maarjamäel asub Eesti Ajaloomuuseum, ent seda teatakse ka kui Suure Isamaasõja ohvrite ja Eestis 1918.-1919. aastal langenud revolutsioonisõdurite nõukogudeaegse memoriaali asupaika. Seal on ka sõjas langenud Saksa sõdurite sümboolne matusepaik, mis rajati praegusel kujul pärast 1991. aastat, pidades silmas ka Saksa relvajõududes teeninud Eesti sõdureid. Maarjamäe lossi tagahoovis paikneb ka nõukogudeaegsete skulptuuride kogu, mis avatakse nõukogude monumentide välinäitusena 2018. aastal. Represseeritute organisatsioonide jaoks kehastas kogu see memoriaalkompleks Maarjamäel aga „okupantide tagahoovi“ ning nad on algusest peale olnud mõtte vastu lisada sinna kommunismiohvrite memoriaal.

Lisaks kohavalikule tekitasid konflikti ka memoriaalile paigutatavate isikute nimed. Memoriaali ettevalmistava komisjoni plaanide kohaselt pidid sellel olema peaaegu 20000 kommunismiohvri nimed. ${ }^{15}$ Seda arvutustele tuginevat arvu pidasid Memento liikmed aga liiga väikeseks. Õispuu tõdes kibedusega, et „ohver on laip“", mõeldes sellega, et meie päevil ei peeta ohvriteks neid, kes repressioonid üle elasid (2016).

Nõnda tuleks represseeritute vastupanu Vabamu ideele vaadata nende kommunismiohvrite tunnustamise poliitika avaramas kontekstis. Peamine partner selles võitluses tunnustamise eest on olnud riik. Seetõttu pole üllatav, et Õispuu pidas ennekõike riiki vastutavaks Okupatsioonide muuseumi status quo taastamise eest (Rohemäe 2016). Idee, et riik peaks muuseumi suhtes olulisemat rolli mängima, pole uus; tegelikult väljendas seda mõtet juba 2003. aastal muuseumi esimene direktor Ahonen (Sildam 2003). Õispuu omakorda kutsus riiki üles muuseumi natsionaliseerima, asendama nii nõukogu kui juhatuse ning palkama esimese direktori muuseumi „väärikust taastama“ (2016), samuti leidis ta, et Okupatsioonide muuseumi asemel võiks muuseumi nimetada kommunismiohvrite muuseumiks.

[15] Nimede kontrollimist korraldas Eesti Mälu Instituut (http://www.mnemosyne. ee/?landing_page=false). 


\section{Okupatsiooni ja vabaduse kontekst: Venemaa ja holokaust}

Diskussioonid Vabamu üle toimusid juba algusest peale ka hargmaises kontekstis, puudutades peamiselt naabermaad Venemaad, aga ka ülemaailmset holokausti mälukultuuri (Levy ja Sznaider 2002).

Nimemuutust tajuti ennekõike kui Venemaa poliitika omaksvõttu mitte üksnes Balti riikide, vaid ka avaramas geopoliitilises kontekstis (Ojakivi 2016; Einmann 2016; Kolga 2016a). 1940. ja 1944. aasta sündmuste hindamise küsimust on seostatud Eesti julgeoleku teemaga, eriti alates pronkssõduri kriisist 2007. aasta aprillis ja sellele järgnenud küberrünnakutest (Herzog 2011). Konflikt Gruusia ja Venemaa vahel (2008) ning Venemaa sõjaline sekkumine Ukrainas alates 2014. aastast on Eestis geopoliitilisi hirme suurendanud.

Sõnast okupatsioon loobumine muuseumi nimes oli märk Venemaa edukast poliitikast ja Eesti finlandiseerumisest nii Eesti äärmuskonservatiivide (näit Helme) kui ka ülemaailmsete inimõiguse aktivistide (näit Kolga) meelest:

Kas ei anna muuseumi ümbernimetamine ja uus suund märku uue poliitkorrektsuse tekkimisest Eestis, pseudofinlandiseerumisest, mis väldib okupatsiooni mainimist, et olla meele järgi idanaabrile? [...] üldiselt arvatakse, et Vladimir Putini üks esmaseid välispoliitilisi eesmärke viimase kümne aasta jooksul on olnud eitada Nõukogude okupatsiooni Balti riikides. [...] Näib, et selle viimase ettevõtmisega on e-Eesti juhtidel õnnestunud võimaldada Putinil teha suur hüpe edasi, unustamaks Nõukogude okupatsioonikuriteod Eestis. (Kolga 2016a, tõlge Kersti Unt)

„Vene argument“ liitis erinevad kriitikute grupid, sest seda on alates iseseisvuse taastamisest pidevalt kasutatud diskussioonides mälukultuuri olevikust ja tulevikust Eestis. Selles ei lahknenud ka vanema ja noorema põlvkonna arvamus, mõlemad leidsid, et Eestil on vaja säilitada (Nõukogude okupatsiooni) mälu, sest Eesti paikneb Vene ohu piirkonnas. Samalaadset argumenti esindasid vaidluste alguses ka muuseumi esindajad. Muuseumi tegevdirektor põhjendas sõna vabadus kasutamist võtmesõnana järgmiselt:

Parem viis [ahvatleda ka nooremat põlvkonda muuseumi külastama] on siduda okupatsioonid vabadusega - millegagi, mida tänapäeval peame meile tagatuks ja mida mõnikord isegi ära ei tunne. Pealegi, vabaduse haprus muutub veelgi ilmsemaks, kui jälgida meie idanaabri ettearvamatuid ettevõtmisi. (Piipuu 2016a, tõlge Kersti Unt)

Ent vastusena konservatiivsete poliitikute katsetele kasutada debatti poliitilistel eesmärkidel kuulutas tegevdirektor muuseumi mittepoliitiliseks asutuseks (BNS 2016). Muuseum nägi Vene turiste ja Eestis elavaid venelasi oma sihtgruppidena, keda on tarvis kaasata. ${ }^{16}$

[16] Vestlus Piipuuga 8. detsembril 2016. 
Ka võrdlust holokausti mälestamisega kasutasid argumendina mõlemad pooled. Muutuste vastased kasutasid holokaustimuuseumide näiteid kogu maailmast kui traumaatilise mineviku esitamise eeskuju. Kõige sagedamini kasutatud argument oli, et "on kujuteldamatu, et üks holokaustimuuseum muudaks nime“ (Helme ja Kelam). Tõmmati paralleel Iisraeliga, mis elab „pidevas ohuseisundis“ ning meenutab juutide kannatusi selleks, et näidata „et juutide vastane vägivald ning juudi riigi hävitamise plaanid ei ole maailmast kusagile kadunud“ (Helme; Einmann 2016). Nii holokausti kui Nõukogude repressioonide ohvrite mälestamine aitaksid selle vaate järgi meenutada maailmale, kui habras võib olla riiklus. Ent samas avaldus kõnealuses diskussioonis ka muutus selles suhtes, kuidas holokaustimälu seotakse stalinlike repressioonide komemoratsiooniga. Nii poliitikud kui ka Baltimaade laiem avalikkus reageeris taastatud iseseisvuse esimestel kümnenditel holokausti teemale emotsionaalselt ja valvsalt ning Eestis holokausti üle eriti ei arutletudki (Pettai 2011: 160). Lisaks tajuti holokausti mäletamise hargmaistumist 2000. aastatel kui midagi, mis püüab võistelda stalinistliku terrori ohvrite mäletamisega. ${ }^{17}$ Vaidlustes Vabamu nime üle aga ei olnud üks teisele kontrastiks, pigem nähti siin seost, sest mõlemad olid võrreldavad ränga rahvusliku trauma mõttes: see on käsitlus, mis läheneb nähtusele, mida nimetatakse mitmesuunaliseks mäluks (Rothberg 2009). Samas tehti võrdlusi siiski riigi ja rahvuse positsioonilt, mitte üldhumanistlikust perspektiivist.

Sellal kui uue nime vastased kasutasid rahvusvahelisi võrdlusi, rõhutamaks kannatuste ajaloo mäletamist sarnastes (rahvuslikes) ohukontekstides, rõhutas Piipuu, et kannatused pole ei eestlaste ega juutide puhul ainus, mis nende identiteeti määrab:

Samas peame meeles pidama, et okupatsioonide aegne kannatus ainü̈ksi ei defineeri, mida tähendab olla eestlane, nii nagu ka holokaust ei defineeri juudirahva aastatuhandete pikkust ajalugu. Kannatus ei tee meid eriliseks, kannatus iseloomustab väga paljusid rahvaid maailmas nii ajaloos kui ka praegu, kuid see, kuidas oleme raskest ajast välja tulnud ja eestlased maailmapildile viinud, on eriline. (Piipuu 2016b)

Piipuu kasutas ka mõistet õpitud ohvripositsioon, tuginedes juutide ja eestlaste kogemuste näidetele, küsides seejuures, mis võiks olla alternatiivsed mäletamisviisid (2016c). Vaidluste algusest alates rõhutas muuseum paljude perspektiivide olulisust selle asemel, et „kuulutada ajaloolist tõde“ (mõeldes selle all ühe minevikuversiooni kui ainuvõimaliku esitamist) (Piipuu kõnest 17. veebruaril 2016). Tuues paralleeli holokausti rollist juutide identiteedis, selgitas muuseum ka oma kavatsust liikuda okupatsioonile tugineva rahvusliku narratiivi juurest edasi.

[17] Näiteks selleks, et integreerida holokausti ohvrite rahvusvaheline mälestuspäev Eesti mälukultuuri, tegi tollane haridusministeerium ettepaneku siduda 27. jaanuari sündmused 25. märtsi mälestus- ja 14. juuni leinapäevaga (Kaas 2002). 


\section{Muutus kui põlvkondadevaheliste erinevuste probleem}

Vaidlused Vabamu nime ümber olid algusest peale seotud põlvkondadevaheliste muutuste tajumisega mälutöös. 1980. aastate lõpust alates on tähendusnihked nõukogude mineviku mäletamises olnud seotud uute põlvkondade esindajate astumisega komemoratsiooniväljale (Kõresaar ja Jõesalu 2016). See, kuivõrd mäletamise väljal tegutsejaid tajutakse põlvkondlikult erinevatena, näitab ühtlasi, kui suurena muutust tajutakse. Vaidlustes Vabamu nime üle kerkis põlvkondadevaheliste muutuste teema mitmel viisil esile nii muuseumis endas kui ka muutuste vastaste leeris.

Esiteks tõstatas põlvkondadevaheliste erinevuste küsimuse muuseum, toetudes oma uue kontseptsiooni ja uue nimega vajadusele kõnetada ka nooremat põlvkonda. Muuseumi suunavõtt noortele algas avalikkuse jaoks 2016. aasta veebruarikuisel üritusel ning see on oluline tänaseni. Vajadust „rääkida okupatsioonide lugu läbi vabaduse kaotamise" seletati vajadusega muuta muuseum noortele paeluvaks (Piipuu 2016a). Muuseumi uusi meetodeid mineviku esitamisel seletati lisaks ka vajadusega kohanduda toimuva põlvkondade vahetusega ühiskonnas: „See, kui klaasi taga näidatakse mõningaid esemeid, äratab mälupilte neis, kes on ise Siberis käinud. Aga välismaalased või noored näevad lihtsalt lusikat ja see ei tekita mingit emotsionaalset reaktsiooni." (Thompson tsit Tigasson 2016)

Muuseumipoolse mineviku ja tuleviku ümbermõtestamise (nii uue püsinäituse kui nimemuutuse mõttes) lähtepunktiks olid nooremad põlvkonnad, kelle kogemushorisont on radikaalselt teistsugune kui kannatanute põlvkonnal. ${ }^{18}$ Mineviku esitamine vabaduse kategooria kaudu tähendas toetumist enamal määral noorte inimeste tänapäevastele kogemustele ja tulevikulootustele, sealhulgas rohkem individualiseeritud vabadusetunnetusele. Piipuu sõnastas nihke minevikukesksuselt tulevikukesksusele ja rõhuasetuste muutust järgmiselt:

... kannatuse narratiiv ei saa panna alust eestimaalaste jätkusuutlikkusele ja tulevikule. [...] tulevik ei vaja kannatajaid - passiivseid ohvreid, vaid tegutsejaid ja aktiivseid kodanikke. (Piipuu 2016c: 101)

Vabamu vastaste jaoks hakkasid muuseumi töötajad ise esindama nooremat põlvkonda, kes olid kaotanud sideme Eesti keerulise minevikuga. Eriti suurt tähtsust omistati alates debati algusest tegevdirektor Piipuule (sünd 1989). Tema noorus, sugu ja varasem karjäär noorteorganisatsioonide juhina olid muuseumi personali teisestamise aluseks nii ajakirjanduses kui sotsiaalvõrgustikes. IT ja idufirma ettevõtja aktiivset osavõttu muuseumi rahastamiskampaaniast peeti küsitavaks. Nõukogu liikme Sten Tamkivi, Skype'i meeskonna endise juhtiva liikme ettepanekut suhtuda Vabamusse kui mõttemaailma start-up'i, nimetati okupatsioonide mäletamisele pühendatud muuseumi puhul absurdihuumoriks (Jõerüüt 2016). Oma startup-põlvkonna kontseptsiooni tõttu (Kolga 2016b), mis juhindub „uusimatest moodsatest start-up filosoofiatest" ega hoia au sees mälestust sõjalisest okupatsioonist, "mille tõttu maa kaotas peaaegu veerandi oma elanikkonnast", peeti küsitavaks selle uue grupi õigust toimida mäluagendina okupatsioonide julmuste meenuta-

[18] Muuseum määratles „noore põlvkonna“ ajaliselt üsna lõdvalt: alates noorematest kui 30-40-aastastest inimestest (Thompson) kuni kooliõpilasteni (Piipuu). 


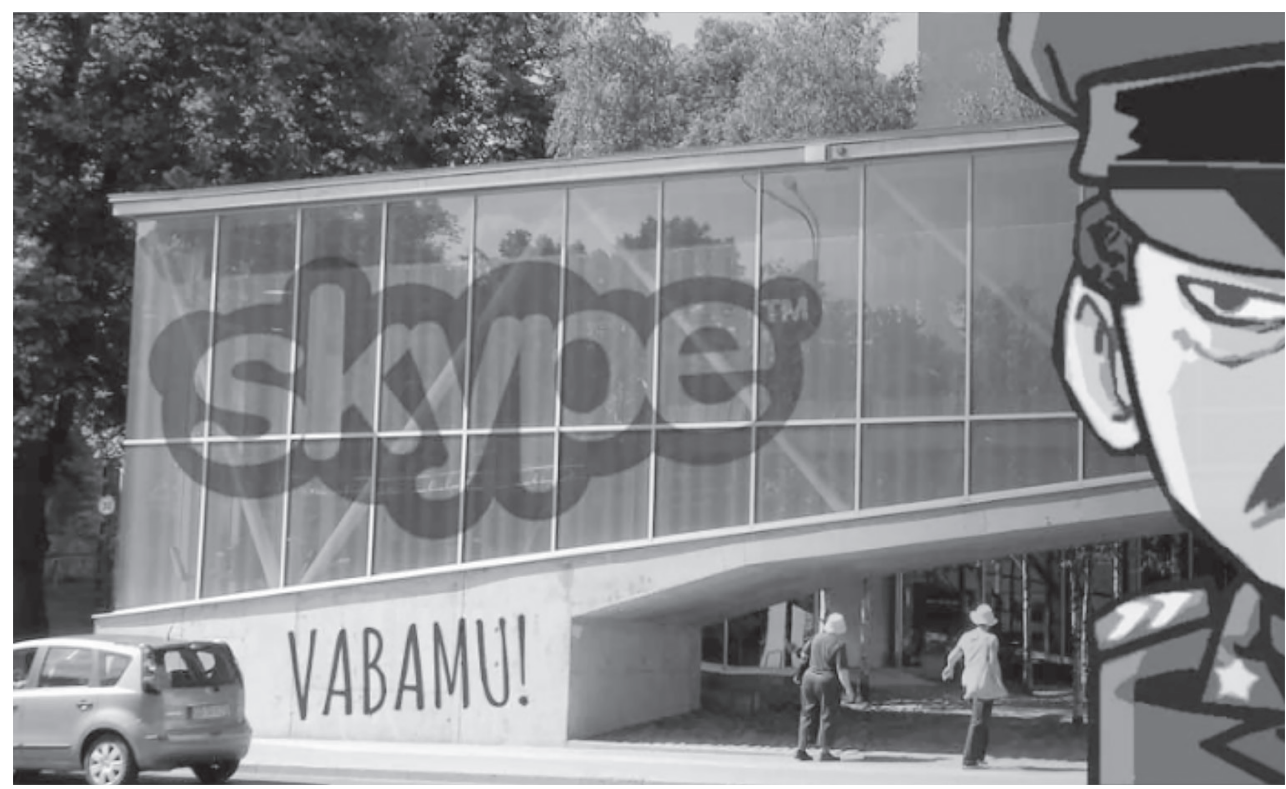

Foto 3. „Tere tulemast eesti E-Okupatsiooni muuseumi"

Allikas: Kolga 2016b

misel. Lisaks leiti, eriti Memento poolt, et nihe vabaduse diskursuse suunas toimub tuluteenimise eesmärgil (Haravee 2016). Lühidalt öeldes süüdistati muuseumi nõukogu selles, et teda pimestab särav kujutis Eestist kui e-tehnoloogia liidrist ning et sellel lastakse nõnda lühinägelikult varjutada märksa olulisemat narratiivi Eesti kannatustest ja ellujäämisest neis (vrd Weekes 2017).

Vabamut tajusid selle vastased kui põlvkondadevaheliste erinevuste probleemi: selle pooldajate eesmärke, (isiklikku) tausta ja kogemust tõlgendati kui põlvkondadevahelise mälu ja solidaarsuse katkestamist ning suhte nõrgendamist Eestiga (Soidro 2016). ${ }^{19}$ Muuseumi katse avardada püsinäituse piire ja selle taustnarratiivi, ajutiste eksponaatide valik, laiemale publikule suunatud avalikud üritused, uuemad haridusprogrammid ning muuseumi üldine suund muutustele rõhutasid vastastes tunnet, et aset leiab põlvkondade konflikt. Muutuste vastased ei eitanud, et muuseumi praegusel püsinäitusel leidub probleeme, millega tuleks tegeleda (Soidro 2016). Tegelikult toetasid nad ka vajadust väljapanekut uuendada (Kelam 2016). Otsustavalt eitati aga muuseumi rõhuasetust olevikule ja tulevikule eesmärgiga tuua minevik noorematele külastajatele lähemale. Mõnede oponentide jaoks oli minevikku vaatamine praeguste individualistlike vabaduste kaudu võrdne rahvusriigi ideest loobumise ja rahvusliku mineviku eitamisega (endine dissident Eve Pärnaste tsit Pullerits 2016; Kolga 2016b). Aktiivne konservatiivne publitsist ja kirjandusteadlane Maarja Vaino (s 1976) sedastas:

[19] Tegelikkuses aga polnud Vabamu pooldajate ja vastaste vahel selget ealist, maailmakogemuselist ega tegevusvaldkondset vahet. 
Oluline on meeles hoida ka seda, et kaasaja kultuuri eest hoolitsemine ei tähenda kultuuri põhialuste ümberdefineerimist või oma ajaloost loobumist. Ning avatus omakorda ei võrdu keskendumisega olevikule, "kaasaegne" olemisele. Ainult olevikule keskenduvad teadupärast üksnes väikesed lapsed. Või inimesed, kel on mälu või reaalsuse tajumisega probleeme. (Vaino 2016)

2016. aasta veebruaris Okupatsioonide muuseumis avatud näitus ja populaarne lastele mõeldud haridusprogramm "Mis teeb kodu koduks?" hakkas muutuste vastaste jaoks tähistama tulemust, mille tooks paratamatult kaasa rängale minevikule lähenemine (ainult) tulevastele põlvedele orienteerumise kaudu. Ajakirjanduses ja sotsiaalmeedias levisid märksõnad, nagu väikelapse/teismelise trotslik hoiak ja lapsik, kirjeldamaks muuseumi tulevast orientatsiooni raske mineviku käsitlemisel. Need märksõnad hakkasid tähistama uut käsitlust, mis ei võimalda mineviku väärikat peegeldust (dignified reflections) (Kolga 2016b). Muuseumi kavatsust kasutada ümberehituse käigus senisest rohkem ära maja keldripinda püsinäituse selliste osade jaoks, mis keskenduvad Saksa ja Nõukogude okupatsioonide julmustele, massipõgenemisele läände 1944. aastal ning argielule paguluses ja Nõukogude Eestis ${ }^{20}$ tõlgendati kui „okupatsiooni tõrjumist silma alt ära, keldrisse“. Oponentide seisukohast võttis muutused kokku irooniline nali ühes kohalikus ajalehes:

Kui siiani võis muuseumi käilakujudeks pidada vabadusvõitlejaid Niklust ja Tartot, siis tulevikus on need suure tõenäosusega Piip ja Tuut. (Soidro 2016)

Orientatsiooni tulevikule Vabamu vabadusekontseptsioonis tajuti erinevana varasemast kontseptsioonist „Mitte kunagi enam!“, mis oli samuti tihedalt seotud tulevikuperspektiiviga. "Mitte kunagi enam!" oli Okupatsioonide muuseumi asutamise juhtiv põhimõte (Thompson 2016). Selle eetiline režiim määratles olevikku läbi muserdava mineviku. Olles universaalne, osutas see ka millelegi kindlale: Eesti puhul ütles see „Mitte kunagi enam!“ kommunistlikule/Venemaa rõhumisele (Baer ja Sznaider 2016). „Mitte kunagi enam“ kui järelmälu režiim eeldas eetilist suhet ohvriga, keskendudes nii rõhumise sisule kui ka järgmistele põlvkondadele suunatud mälutööle (Hirsch 1997). Vabamut tajuti kui midagi, mis püüab algatada sootuks teistsugust suhet minevikuga. ${ }^{21}$ Paljude perspektiivide esitamist kehtiva ohvritest ja vastupanust kõneleva narratiivi asemel nähti kui eetilise hoiaku allakäiku suhtumisel ohvrisse. Seoste tõttu Eesti digitaalse identiteedi ning „,ettevõtluse vabaduse“, aga ka muuseumi uute programmide mängulisuse tõttu tundus Vabamu - nii nimena kui kontseptsioonina, mida see tähistas - traumat trivialiseerivat ning käsitlevat rasket minevikku lihtsalt kui igapäevaelu järjekordset aspekti. Ehkki just selline dünaamiline nihe järelmälu osas leiab aset ka mujal Euroopas, eriti holokaustifilmides (Bayer 2010), peeti seda Eestis soovimatuks eemaldumiseks praegusest mälukultuurist.

[20] Muuseumi plaan laiendada ekspositsiooni keldrisse tuleneb maja arhitektuursest eripärast. Esimene korrus on suur avatud ruum, mille seinad on klaasist. Suletud keldrikorrus võimaldab palju mitmekülgsemaid näituselahendusi.

[21] Sama tajusid ka muutuste pooldajad (nt Metlev 2016). 


\section{Kokkuvõte}

Vaidlused Vabamu nime ümber tõid eredalt esile selle, kuidas nimetamine ja ümbernimetamine sedastavad ideoloogilisi sõnumeid mineviku ja oleviku kohta. Debatt osundas ümbernimetamisele kui aktiivsele ja vaieldavale mälupoliitilisele protsessile. Okupatsioonide muuseumi vaatenurgast oli katse võtta uueks nimeks Vabamu ühtlasi püüe avardada kannatuste ja ellujäämisdiskursuse piire, mille kitsendavat ja hegemoonilist mõju muuseum tajus. Samuti oli nimemuutus katse muuta muuseum kaasavamaks eri ühiskonnagruppide ja nende kogemuse ja tulevikuootuste suhtes.

Võttes mälutöö suhtes pluralistliku positsiooni, ${ }^{22}$ oli muuseumi pilk pööratud pigem hargmaiste mõjutuste kui rahvusliku mälukogukonna poole. Barbara Törnquist-Plewa on näidanud, et rahvusliku ja kosmopoliitse perspektiivi põrkumine iseloomustab paljusid 21. sajandi vastuolusid Ida- ja Kesk-Euroopas möödunud sajandi vägivaldse minevikuga tegelemisel (Törnquist-Plewa 2016: 212). Kuigi nimemuutuse vastased opereerisid Vabamu debatis samuti hargmaiste mälestusstrateegiatega (holokaust), oli nende keskmes pigem järjepidevus mäletamispraktikates kui dünaamika. Loobumine sõnast okupatsioon vallandas ohvrite põlvkonna omandinõuded minevikule reaktsioonina katsele anda raske mineviku eestkosteõigus üle „e-põlvkonnale, kelle side Eestiga on nõrgenenud“. „Okupatsioonist loobumist" tõlgendati üldisemalt kui eemaldumist Eesti identiteedi põhinarratiivist. Võib väita, et mingis mõttes paljastas see vaidlus erinevaid arusaamu 20. sajandi kogemusest, eriti aga Nõukogude okupatsioonist. Samuti aktiveerusid Vabamu debatis sellised olulised mäletamise raamistikud nagu Eesti-Vene suhete ebastabiilsus ning holokausti mäletamine autoritaarse mälurežiimina. Iseäranis Eesti-Vene suhete kontekstis anti okupatsioonide mäletamisele julgeolekupoliitiline mõõde. Okupatsioonimälu julgeolekustamine Vabamu debatis viitab Eesti mälukultuuri resistentsuse ühele peapõhjusele - nn Vene ohule, mida tajutakse eksistentsiaalse ohuna, pideva väljakutsena Eesti riigi püsimajäämisele „iseendana“ (Mälksoo 2015).

2011. aastal toimunud uuringu „Mina, maailm, meedia” tulemused lisavad ülaltoodule intiimsema personaalse ja perekondliku perspektiivi. Sotsiaalantropoloog Inge Melchior on uuringu andmeid analüüsides näidanud, et ligi 70\% eestlastest pidas oluliseks mingis vormis tseremoniaalset komemoratsiooni Nõukogude massirepressioonide ohvrite mälestamisega seotud riiklikel tähtpäevadel (sh umbes $58 \%$ vanusevahemikus 15-29). Eriti kõrgharitud vastajad, kelle mõju ühiskonnas on eeldatavalt suurem, omistasid suurt tähtsust repressioonimineviku järjepidevale mäletamisele ja kollektiivsele mälestamisele (Melchior 2015: 162-164). Need arvud näitavad, et valdavalt tunti moraalset kohustust kaitsta olemasolevat mälurežiimi ka suhtelise julgeoleku aegadel. Melchiori arvates on eestlaste emotsionaalne seotus rahvuse minevikuga otseselt seotud peremäluga: „rahva lugu on pere lugu“ (Melchior 2015: 295). See teeb rahvusliku narratiivi kui kultuurimälu vormi isiklikuks ka järelmälu-põlvkondade jaoks. Mõiste okupatsioon on üks selle seotuse süm-

[22] Vrd memory pluralists (Bernhard ja Kubik 2014: 17). 
boleid. Isegi kui üle 40\% eestlastest oli 2011. aastal arvamusel, et mineviku pidev kaasavedamine võib takistada Eesti arengut tulevikus (Melchior 2015: 163), näitab Vabamu debatt, et ajaloomälu kesksete sümbolite ohtu sattumine käivitab hirmud ja aktualiseerib moraalse kohustuse ühist minevikku säilitada.

2017. aasta märtsis uusi näituseplaane avaldades tuli muuseum välja ka uue nimega: Okupatsioonide ja vabaduse muuseum Vabamu. Uus nimi ei tekitanud mingeid tähelepanuväärseid reaktsioone. See, et vaidlused Vabamu ümber toimusid ennekõike sõna okupatsioon pärast nimes ning sellepärast, mida see tähistas, on selge ka asjaolus, et muuseumi uus lähenemine kodanikuharidusele ajutiste näituste kaudu on juba suurendanud külastajate arvu. Debati esimese nelja kuu jooksul külastas muuseumi rohkem inimesi kui kogu 2015. aasta jooksul kokku. Peaaegu pooled neist olid õpilased (Ernits 2016).

Tagasivaates möönis muuseum, et neil polnud aimugi, kui „stressis“ mäletamise väli tegelikult on. ${ }^{23} 2016$. aasta aprillikuust alates on otsitud kompromissi muuseumi plaanide ja avalikkuse ootuste vahel. Kui debati algfaasis püüdis muuseum end kannatuste narratiivist lahti siduda, siis 2016. aasta kevadeks eelistati rääkida narratiivi viimisest nende inimgruppideni, kes olid varem näituselt välja jäänud. ${ }^{24}$

Juba enne uue püsinäituse avamist on Okupatsioonide muuseum tekitanud vaidluse selle üle, mis loob Eesti mälu ja mis on Eesti mälukultuuri sisuks. Siin on potentsiaali ajaloomälu positiivseks (taas)politiseerimiseks (vrd Mälksoo 2015), et suurendada ühiskonna eneserefleksiivsust. Tuleb oodata uue püsinäituse avamist, et näha, kas debatt on määratud jätkuma.

\section{Allikad ja kirjandus}

Ahonen, Heiki. 2005. Wie gründet man ein Museum? Zur Entstehungsgeschichte des Museums der Okkupationen in Tallinn. - Knigge, Volkhard, Ulrich Mählert (Hg.) Der Kommunismus im Museum. Formen der Auseinandersetzung in Deutschland und Ostmitteleuropa. Köln: Böhlau, 107-116.

Alderman, Derek H. 2002. Street Names as Memorial Arenas: The Reputational Politics of Commemorating Martin Luther King in a Georgia County. - Historical Geography 30: 99-120.

Allah Pugatchova. http://pugatchova.blogspot.com.ee/2016/02/, 27.02.2016 (viimati külastatud 15.10.2017).

Anepaio, Terje. 2002. Reception of the Topic of Repressions in the Estonian Society. - Pro Ethnologia 14: 47-65.

Ashplant, Timothy G.; Graham Dawson; Michael Roper. 2004. The Politics of War Memory and Commemoration: Contexts, Structures and Dynamics. - Timothy G. Ashplant; Gra-

[23] Vestlusest Piipuuga 13.10.2016.

[24] Vestlusest Piipuuga 8.12.2016 Okupatsioonide muuseumis, arutades Piipuu ettekannet „From the narrative of suffering to the value of freedom: What does it mean to rebuild a museum within the memory landscape of a former Soviet Union republic?" (Stanfordi Ülikooli raamatukogus, 7. novembril 2016). Sügisel 2016 maakonnalehtedes avaldatud arvamusloo kohaselt kinnitas direktor, et "ideoloogilist muutust“ ei tule; muuseum tahab muuta vaid viisi, kuidas lugusid jutustatakse (Piipuu 2016d). 
ham Dawson; Michael Roper (eds.) Commemoration of War. New Brunswick, New Jersey: Transaction Publisher, 3-85.

Baer, Alejandro; Natan Sznaider. 2016. Memory and Forgetting in the Post-Holocaust Era: The Ethics of Never Again. London: Routledge.

Bayer, Gerd. 2010. After Postmemory: Holocaust Cinema and the Third Generation. - Shofar: An Interdisciplinary Journal of Jewish Studies 28 (4): 116-132.

Berg, Lawrence D.; Robin A. Kearns. 1996. Naming as Norming: 'Race', Gender, and the Identity Politics of Naming Places in Aotearoa/New Zealand. - Environment and Planning D: Society and Space 14: 99-122.

Bernhard, Michael H.; Jan Kubik. 2014. The Theory of the Politics of Memory. - Michael H. Bernhard, Jan Kubik (eds.) Twenty Years After Communism: The Politics of Memory and Commemoration. Oxford University Press, 7-36.

BNS 2016 = Direktor: poliitika ei tohiks mõjutada okupatsioonimuuseumi nime. - Postimees, 10.03.2016. http://www.postimees.ee/3613503/direktor-poliitika-ei-tohiks-mojutada-okupatsioonimuuseumi-nime, viimati vaadatud 24.10.2017.

Brodsky, Patricia Pollock. 2001. The Power of Naming in the Postunification Attack on the German Left. - Nature, Society, and Thought 14 (4): 419-500.

Doronenkova, Kristine. 2011. Official Russian Perspectives on the Historical Legacy: A Brief Introduction. - Nils Muižnieks (ed.) The Geopolitics of History in the Latvian-Russian Relations. Riga: Academic Press of the University of Latvia, 21-30.

Ehin, Piret; Eiki Berg. 2009. Incompatible identities? Baltic-Russian Relations and the EU as an Arena of Identity Conflict. - Piret Ehin, Eiki Berg (eds.) Identity and Foreign Policy: Baltic-Russian Relations and European Integration. Farnham; Burlington: Ashgate Publishing, $1-14$.

Einmann, Andres. 2016. Helme: okupatsioonide muuseumi nimevahetus saadab maailmale vale sõnumi. - Postimees, 22.02.2016. http://www.postimees.ee/3592705/helme-okupatsioonide-muuseumi-nimemuutus-saadab-maailmale-vale-sonumi, viimati vaadatud 24.10.2017.

Ein studentischer Erfahrungsbericht 2005. Kommunismus zum Anfassen? Museen zur Geschichte der kommunistischen Diktaturen in Ostmitteleuropa. - Knigge, Volkhard; Mählert, Ulrich (Hg.) Kommunismus im Museum: Formen der Auseinandersetzung in Deutschland und Ostmitteleuropa. Wien, Köln, Weimar: Böhlau, 193-223.

Ernits, Rutt. 2016. Okupatsioonide muuseum lõi viie kuuga külastusrekordi. - Kultuur.err. ee, 20.06.2016. http://kultuur.err.ee/312679/okupatsioonide-muuseum-loi-viie-kuugaaastase-kulastusrekordi, viimati vaadatud 24.10.2017.

Haravee, Juhan. 2016. Okupatsioonide muuseumi nimevahetus tekitab pahameelt. - Õhtuleht, 5.03.2016. http://www.ohtuleht.ee/721202/okupatsioonide-muuseumi-nimevahetustekitab-pahameelt, viimat vaadatud 24.10.2017.

Herzog, Stephen. 2011. Revisiting the Estonian Cyber Attacks: Digital Threats and Multinational Responses. - Journal of Strategic Security 4 (2): 49-60. DOI: http://dx.doi. org/10.5038/1944-0472.4.2.3.

Hirsch, Marianne. 1997. Family Frames: Photography, Narrative and Postmemory. Cambridge, MA: Harvard University Press.

Jõerüüt, Jaak. 2016. Idee toppida vabadus ühte muuseumisse ja hakata seda seal arendama on absurdne. - Postimees, 4.04.2016. http://arvamus.postimees.ee/3642085/jaak-joeruutidee-toppida-vabadus-uhte-muuseumisse-ja-hakata-seda-seal-arendama-on-absurdne, viimati vaadatud 24.10.2017. 
Jõesalu, Kirsti; Ene Kõresaar. 2013. Continuity or Discontinuity: On the Dynamics of Remembering "Mature Socialism" in Estonian Post-Soviet Remembrance Culture. - Journal of Baltic Studies, 44 (2), 177-203.

Kaas, Kaarel. 2002. Holokaustipäev toob küüditatute mälestamise. - Postimees, 08.11. 2002, https://www.postimees.ee/1978481/holokaustipaev-toob-kuuditatute-malestamise, viimati külastatud 24.10.2017.

Kearns, Robin A.; Lawrence D. Berg. 2002. Proclaiming place: Towards a geography of place name pronunciation. - Social \& Cultural Geography 3 (3): 283-302. DOI: 10.1080/1464936022000003532.

Kelam, Tunne. 2016. Okupatsioonide muuseumist ei peaks saama paik, kuhu noored lähevad mõnusalt aega veetma. - Postimees, 26.02. 2016. http://arvamus.postimees.ee/3597669/ tunne-kelam-okupatsioonide-muuseumist-ei-peaks-saama-paik-kuhu-noored-laehevad-monusalt-aega-veetma?_ga=1.252282509.560156530.1471268295, viimati külastatud 24.10.2017.

Knigge, Volkhard; Ulrich Mählert (Hg.). 2005. Der Kommunismus im Museum: Formen der Auseinandersetzung in Deutschland und Ostmitteleuropa. Köln: Böhlau.

Kolga, Marcus. 2016a. Welcome to the e-Occupation Museum. - ERR News, 22.2.2016. http:// news.err.ee/v/opinion/323cddeb-fffb-4d9b-966f-26c64d870f34/marcus-kolga-welcometo-the-e-occupation-museum, viimati külastatud 24.10.2017.

Kolga, Marcus. 2016b. Welcome to Estonia's E-Occupation Museum. - Up North, 17.3.2016. http://upnorth.eu/welcome-to-estonias-e-occupation-museum/, viimati külastatud 24.10. 2017.

Kooli, Rain. 2016. Okupatsioonist vabad või vabadusega okupeeritud? - ERR Uudised 11.04.2016. http://www.err.ee/557761/rain-kooli-okupatsioonist-vabad-voi-vabadusegaokupeeritud, viimati külastatud 25.10.2017.

Kõresaar, Ene. 2004. The Notion of Rupture in Estonian Narrative Memory: On the Construction of Meaning in Autobiographical Texts on the Stalinist Experience. - Ab Imperio 4: 313-339.

Kõresaar, Ene; Kirsti Jõesalu. 2016. Estonian memory culture since the post-communist turn: conceptualizing change through the lens of generation. - Raili Nugin, Anu Kannike, Maaris Raudsepp (eds.) Generations in Estonia: Contemporary Perspectives on Turbulent Times. Tartu: Tartu University Press, 128-156.

Kuusi, Hanna. 2008. Prison Experiences and Socialist Sculptures - Tourism and the Soviet Past in the Baltic States. - Auvo Kostiainen, Taina Syrjämaa (eds.) Touring the Past. Uses of History in Tourism. Discussion and Working Papers. 6 / Keskusteluajaraportteja 6. Savonlinna: The Finnish University Network for Tourism Studies (FUNTS) Matkailualanverkostoyliopisto (MAVY), 105-122.

Levy, Daniel; Natan Sznaider. 2002. Memory Unbound: The Holocaust and the Formation of Cosmopolitan Memory. - European Journal of Social Theory 5 (1): 87-106. DOI:10.1177/1 368431002005001002.

Light, Duncan; Craig Young. 2014. Habit, Memory, and the Persistence of Socialist-Era Street Names in Postsocialist Bucharest, Romania. - Annals of the Association of American Geographers 104 (3): 668-685.

Mälksoo, Maria. 2009. “The Memory Politics of Becoming European: The East European Subalterns and the Collective Memory of Europe". - European Journal of International Relations 15 (4): 653-680. DOI: 10.1177/1354066109345049.

Mälksoo, Maria. 2015. Mäluseadused ja julgeolek. - Vikerkaar 10-11: 120-128.

Mark, James. 2008. Containing Fascism: History in Post-Communist Baltic Occupation and Genocide Museums. - Oksana Sarkisova, Péter Apor (eds.) Past for the Eyes: East European 
Representations of Communism in Cinema and Museums after 1989. Budapest and New York: CEU Press, 335-369.

Mechior, Inge. 2015. Guardians of Living history. The Persistence of the Past in Post-Soviet Estonia. Amsterdam: Vrije Universiteit, 2015.

Ministry of Defence of Republic of Moldova. An Exhibition Dedicated to Soviet Occupation Period Opens at Military Museum. Ministry of Defence. http://www.army.md/?lng=3\&actio $\mathrm{n}=$ show\&cat $=122 \&$ obj $=3759 \#$.WScwlrFh2Rs

Muižnieks, Nils. 2011. History, memory and Latvian Foreign Policy. - Nils Muižnieks (ed.) The Geopolitics of History in the Latvian-Russian Relations. Riga: Academic Press of the University of Latvia, 7-18.

Nõukogude okupatsioonimuuseum Gruusias, Tbilisis. http://museum.ge/index.php?lang id=ENG\&sec_id=53, viimati külastatud 24.10. 2017.

Ojakivi, Mirko. 2016. Enn Tarto on okupatsioonide muuseumi nime muutuse vastu. - ERR uudised, 21.2.2016. http://uudised.err.ee/v/d8d9b804-b657-40ec-8d26-3152c9cf0e55, viimati külastatud 25.10.2017.

Onken, Eva-Clarita. 2007. The Baltic States and Moscow's 9 May Commemoration: Analysing Memory Politics in Europe. - Europe-Asia Studies 59 (1): 23-46.

Palonen, Emilia. 2008. The City-Text in Post-Communist Budapest: Street Names, Memorials, and the Politics of Commemoration. - GeoJournal 73: 219-230. DOI 10.1007/s10708008-9204-2.

Pettai, Eva Clarita. 2011. Establishing 'Holocaust Memory'. A Comparison of Estonia and Latvia. - Oliver Rathkolb, Imbi Sooman (eds.) Historical Memory Culture in the Enlarged Baltic Sea Region and its Symptoms Today. Göttingen: Vandenhoeck \& Ruprecht, 159-174.

Piipuu, Merilin. 2016a. Remembering the occupations will remain at the heart of the museum. ERR News, 25.2.2016. http://news.err.ee/117695/merilin-piipuu-remembering-theoccupations-will-remain-at-the-heart-of-the-museum, viimati külastatud 25.10.2017.

Piipuu, Merilin. 2016b. Okupatsioonide Muuseumi tegevdirektor - okupatsioonidest vabaduseni. - Õhtuleht, 8.3.2016: 8.

Piipuu, Merilin. 2016c. Mis mahub kannatuste vahele? Marginaalia Eesti lähiajaloos, Vikerkaar 7-8: 96-101.

Piipuu, Merilin. 2016d. Mäletada ja teenida vabadust? Kuidas? - Virumaa Teataja, 6.09.2016: 2.

Pöördumine $=$ Pöördumine Okupatsioonide muuseumi nime küsimuses. - Kultuur $\mathcal{E}$ Elu 2, 2016. http://kultuur.elu.ee/ke524_Okupatsioonide_muuseum.htm

Põld, Anna. 2016a. Okupatsioonide muuseumi nimevahetusega kardetakse muuseumi algse idee kadumist. - Delfi, 28.2.2016. http://www.delfi.ee/news/paevauudised/ eesti/okupatsioonide-muuseumi-nimevahetusega-kardetakse-muuseumi-algse-ideekadumist?id=73784551, viimati külastatud 25.10.2017.

Põld, Andres. 2016b. Lagle Parek: okupatsioonis on lihtsam, vabaduses aga parem elada! Öhtuleht, 16.4.2016: 6-7.

Pullerits, Priit. 2016. Eve Pärnaste: varasemast leebem, aga ikka võitluslik. - Postimees, 30.4.2016. http://www.postimees.ee/3673447/eve-paernaste-varasemast-leebem-aga-ikkavoitluslik (viimati külastatud 25.10.2017).

Radio Free Europe 2015. Kyiv City Council Approves Open-Air Museum of Soviet 'Occupation'. 15.7. 2015. https://www.rferl.org/a/ukraine-kyiv-museum-soviet-occuptaiton/27149365. html, viimati külastatud 25.10.2017.

Radonič, Liljana. 2017. Post-Communist Invocation of Europe: Memorial Museums' Narratives and the Europeanization of Memory. - National Identities 19 (2): 269-288. 
Rohemäe, Maria-Ann. 2016. Kommunismiohvrid taunivad Okupatsioonide muuseumi uut nime. - ERR Uudised, 27.3.2016 http://uudised.err.ee/v/10055fee-0fb4-4880-ba08-01d0dfc23e92, viimati külastatud 25.10.2017.

Rothberg, Michael. 2009. Multidirectional Memory: Remembering the Holocaust in the Age of Decolonization. Stanford: Stanford University Press.

Sepp, Heili. 2016. Ajaloost, mälust ja märkidest. - Eesti Ekspress, 6.4.2016 http://ekspress.delfi.ee/arvamus/heili-sepp-ajaloost-malust-ja-markidest?id=74114363, viimati külastatud 25.10.2017.

Sildam, Toomas. 2003. Okupatsioonide muuseum võtab ette lähiajaloo uurimise. - Postimees, 28.6.2003: 3 .

Smith, David J. 2008. Woe from Stones: Commemoration, Identity Politics and Estonia's 'War of Monuments. - Journal of Baltic Studies 39 (4): 419-430.

Soidro, Mart. 2016. Hundid söönud, lambad murtud? - Saarte Hääl, 1.3.2016. https://www. meiemaa.ee/index.php?content=artiklid\&sub=2\&artid=69022, viimati külastatud 25.10 . 2017.

Taavetti, Riikka. (ilmumas). Queering Victimhood? Socialist Legacies and Queer Pasts in and around Jaanus Samma's "NSFW. A Chairman's Tale". - Kirsti Salmi-Niklander, Sofia Laine, Päivi Salmisvouri (eds.) Livingmemories. Living Together with Difficult Memories and Diverse Identities.

Tamm, Marek. 2012. Mälupoliitika. - Raivo Vetik (toim). Eesti poliitika ja valitsemine 1911-2011. Tallinn: Tallinna Ülikooli Kirjastus. (Acta Universitatis Tallinnensis. Socialia), 144-185.

Thompson, Sylvia 2016. Kõne Eesti Vabariigi iseseisvuspäeva tähistamisel, Sunnyvale, California. 27.2.2016. http://www.okupatsioon.ee/images/thompson_speech.pdf, viimati külastatud 25.10.2017.

Tigasson, Külli-Riin. 2016. „Vabamu” kõlab nagu „Kumu”. Miks peab okupatsioonide muuseumist saama Vabamu? Ekspress kohtus okupatsioonide muuseumi asutaja Olga Kistler-Ritso tütre Sylvia Kistler Thompsoniga. - Eesti Ekspress, 20.4.2016. http://ekspress.delfi.ee/kuum/vabamu-kolab-nagu-kumu?id=74272035, viimati külastatud 25.10.2017.

Troebst, Stefan. 2007. 'Budapest' oder, 'Batak'? Varietäten südosteuropäischer Erinnerungskulturen”. Ulf Brunnbauer, Stefan Troebst (Hrsg). Zwischen Amnesie und Nostalgie. Die Erinnerungan den Kommunismus in Südosteuropa. Köln: Böhlau, 15-26.

Törnquist-Plewa, Barbara. 2016. Local Memories under the Influence of Europeanization and Globalization: Comparative Remarks and Conclusions. - Barbara Törnquist-Plewa (ed.). Whose Memory? Which Future?: Remembering Ethnic Cleansing and Lost Cultural Diversity in Eastern, Central, and Southeastern Europe. New York: Berghahn Books, 208-226.

Zhurzhenko, Tatiana. 2007. The Geopolitics of Memory. - Eurozine, 10.05.2007, www.eurozine.com, viimati külastatud 25.10.2017.

Uuring 2016: Vabamu nime toetab vaid 10 protsenti Eesti kodanikest. - ERR Uudised, 22.6. 2016. http://uudised.err.ee/v/f27edc23-c6fa-4fda-a00b-77109bbee139, viimati külastatud 25.10.2017.

Vaino, Maarja. 2016. Avatus ei tohiks tähendada suletust mineviku ees. - ERR uudised. 25.2. 2016. http://kultuur.err.ee/v/arvamus/00d58a65-17e2-467a-940f-ef2fad277b4c/maarjavaino-avatus-ei-tohiks-tahendada-suletust-mineviku-ees (viimati külastatud 25.10.2017).

Velmet, Aro. 2011. Occupied Identities: National Narratives in Baltic Museums of Occupations. - Journal of Baltic Studies 42 (2): 189-211. DOI: 10.1080/01629778.2011.569065.

Vukov, Nikolai. 2007. Protean Memories, 'Permanent' Visualizations: Monuments and History Museums in Post-Communist Eastern Europe. - Ene Kõresaar, Epp Lauk, Kristin Kuutma (eds.) The Burden of Remembering: Recollections and Representations of the 20th Century. Helsinki: SKS, 139-159. 
Weekes, Lorraine. 2017. Debating Vabamu: Changing names and narratives at Estonia's Museum of Occupations. - Cultures of History Forum, 25.04. 2017. http://www.cultures-ofhistory.uni-jena.de/debates/estonia/debating-vabamu-changing-names-and-narrativesat-estonias-museum-of-occupations/\#fn-text7, viimati külastatud 25.10.2017.

Õispuu 2016 = Leo Õispuu kõne massiküüditamise ohvrite mälestuspäeval 25. märtsil, Okupatsioonide muuseumis. https://www.youtube.com/watch?v=Z64vSFGKkeo, viimati külastatud 25.10.2017. 


\section{Summary: From "Museum of Occupations" to "Vabamu": analysis of naming policy}

\section{Ene Kõresaar, Kirsti Jõesalu}

This article focuses on the debate around the name Vabamu and is aimed at discussing whether and how the culture of remembering the Soviet era can change in today's Estonia. In February 2016, the Estonian Museum of Occupations announced its plans to refresh its identity and change the name of the museum to the Museum of Freedom Vabamu. The planned name change sparked controversy in society about the meaning of the (Soviet) military occupation, the sufferings of that period and ways of commemorating them. Over 60 stories were published in the Estonian media from February to August 2016, accompanied by lively discussion on social media. Estonia's Russianlanguage media did not participate in the discussion.

The article analyses the Vabamu name debate in the context of naming policy and Estonian 20th century historical memory. First of all, the term of "occupation" is explained from the aspect of Estonia's political identity and Baltic, Russian and European relations. Secondly, the article analyses the main voices and topics in the debate and which of the current memory regime's models and frameworks of memory policy emerged. It asks, from the perspective of memory studies, why the name change to "Vabamu" was not carried out according to original plans.

The main sources of the analysis were texts in the media; including social media; interviews with the museum director, participatory observations at meetings of the museum's advisory board, and at meetings and temporary exhibitions organized by the museum. In addition to documenting the development of the name debate, the participation, observation and interviews made it possible to explore the conceptual objectives behind the name "Vabamu".

The following opinions resonated in discussions: (1) opinions of the Memento organization (which advocates for the rights of those who suffered persecution by the Soviet regime) and Sovietera dissidents in media opinion pieces and segments and public statements; (2) statements made by politicians (mainly rightconservatives); (3) opinions from members of the Estonian émigré community; (4) statements from museum managing director Merilin Piipuu and the chairwoman of the KistlerRitso foundation Sylvia Thompson, which reflected the museum's intentions; and (5) the public discussion initiated by the museum.

A key date in the development of the debate was 25 March 2016, the anniversary of mass deportations in 1949 when also the representatives of Memento organization voiced their opinion. Giving up "occupation" in the name of the museum occasioned property claims of the generation of victims of communism. The repressed people considered the Museum of Occupation their symbolic place. For this group, the disappearance of the word "occupations" from the museum name actualized the complexity of policy of recognizing their experience ever since the late 1980s. The debate regarding the establishing of a memorial to victims of communism in Tallinn also had an influence. 
The discussions over "Vabamu" were held in a transnational context, pertaining mainly to neighbouring Russia, and the global Holocaust memory culture. The name change was perceived above all as an adoption of Russian memory politics, not just in the context of the Baltic states but in the broader geopolitical context. Giving up the word "occupation" was seen by critics - and at the outset of the debate by the museum as well - as a national security issue. As the discussion evolved, the museum distanced itself from the security discourse and cited Russian tourists and Estonian Russians as target groups that needed to be reached and included.

The comparison to the Holocaust memory culture was also used as an argument by both parties. The opponents of the new name used international comparisons to stress the remembering of the violent past in similar (national) threat contexts. On the other hand, the museum used the Holocaust argument from the standpoint of Jewish identity to justify its intention to move further past the national narrative of occupation.

The debates over the name Vabamu were also related to a perception of intergenerational changes in memory work. The museum was reconceptualising the past and future to reach out to younger generations whose experience horizon is radically different from that of the generation of the victims of repressions and whose sense of freedom is more individualized. For opponents of "Vabamu", the museum staff themselves represented the younger generation who no longer had a link to Estonia's past ordeals and for whom intergenerational memory and solidarity had become interrupted. Their preference for a multiperspective narrative in place of a narrative of victimhood and resistance was interpreted as an ethical softening toward the victims and trivialization of trauma.

As a result of the name debate, the museum decided to forgo a radical change in the name and opted for a compromise: Vabamu, the Museum of Occupations and Freedom. The debate over the concept of occupation showed the importance of linguistic definitions in a more extensive battle over how the past is represented. The concept of occupation has been the core of political identity both in postcommunist Estonia and the other two Baltics. The term "occupation" is related to all of the key elements in Estonia's postcommunist narrative. Associating the memory of the (Soviet) occupation with security policy in the Vabamu debate points to a main reason for persistence of Estonian current memory culture - the socalled Russian threat, which is perceived as an existential danger, a constant challenge to the survival of the Estonian state. Earlier studies have shown that for Estonians, personal, social, cultural and political memory is strongly interwoven when remembering the 20th century: the national story is strongly supported by family stories. This makes the national narrative personal. When central symbols of the historical memory come under fire, fears are stoked and appeals to a moral duty to preserve a common past are heard. 
Резюме: От Музея оккупаций к Vabamu: анализ политики наименования

\section{Эне Кыресаар, Кирсти Йыесалу}

Статья концентрируется В фокусе статьи дебаты о названии Vabamu с целью обсудить возможности изменения сохранившихся о советском периоде воспоминаний в современной Эстонии. В феврале 2016 года Музей оккупаций объявил о своих планах обновления и желании изменить название музея - на Музей свободы Vabamu. План изменения названия вызвал в обществе горячие споры о значении (советской) военной оккупации, тогдашних страданий и памяти о них. С февраля по август в эстонской медиа было опубликовано более 60 статей, которые сопровождались оживленной дискуссией в социальных медиа. Русскоязычные медиа Эстонии в дискуссии участия не принимади.

В статье анализируются дебаты, связанные с названием Vabamu в контексте политики наименования и исторической памяти Эстонии XX века. Во-первых, разъясняется подитика понятия «оккупация», исходя из аспекта подитического идентитета Эстонии и отношений стран Балтии, России и Европы. Во-вторых, анадизируются основные участники и темы дебатов, а также то, какие модели современного режима памяти и какие рамки политической памяти выявидись. С точки зрения исследования памяти поставлен вопрос о том, почему изменение названия Vabamu не осуществилось в соответствии с первоначальным планом

Основными источниками анализа послужили тексты медиа и социальных медиа, интервью с руководителем музея, участие в роли наблюдателя на встречах с консультативной палатой, на организованных музее мероприятиях и временных выставках. Участие, наблюдение и интервью позволили помимо документирования дебатов о названии открыть и стоящие за названием Vabamu концептуальные цели.

В дискуссиях прозвучали следующие мнения: (1) мнения представителей общества Memento и диссидентов советского времени в виде комментариев в медиа и публичного выражения своей позиции; (2) позиции политиков (в основном право-консервативных); (3) мнения известных деятелей культуры; (4) мнения членов общины проживающих за рубежом эстонцев; (5) озвучивающие планы музея выступления исполнительного директора музея Мерилин Пийпуу и председателя ЦУ Кистлер-Ритсо Сильвии Томпсон и (6) инициированное музеем публичное обсуждение.

Важным моментом в развитии дебатов стал день памяти жертв массовых репрессий 25 марта 2016 года: в этот день публично выразили свое мнение и представители Эстонского общества Memento. Отказ от слова «оккупация» вызвало требования собственности поколения жертв к своему прошлому. Репрессированные считали Музей оккупаций своим символом. Исчезновение из названия музея 'оккупаций' актуализировало для репрессированных их опыт, связанный со сложностью подитики признания, начиная с конца 1980-х годов. Свое вдияние оказал и имевший в то время место спор о возведении в Таллинне мемориала жертвам коммунизма. 
Дискуссии о Vabamu происходиди в транснациональном контексте, затрагивая в основном соседнее государство - Россию, а также всемирную культуру сохранения памяти о жертвах Холокоста. Изменение названия было воспринято прежде всего, как признание политики памяти России и не только в странах Балтии, но и в более широком геополитическом контексте. Критики трактовали отказ от 'оккупации' в названии музея - а в начале дебатов и музей - как вопрос безопасности. В процессе развития дискуссии музей отошел от дискурса безопасности ссылаясь на российских туристов и проживающих в Эстонии русских как на нуждающиеся в привлечении целевые группы. Обе стороны в качестве аргумента также исподьзовали сравнение с памятью о жертвах Холокоста. Противники нового названия использовали международные сравнения подчеркивая память об истории страданий в похожих (государственных) контекстах надичия опасности. Музей, напротив, исподьзовад аргумент Ходокоста в идентитете евреев для того, чтобы обосновать свои намерения продвинуться дальше от опирающегося на оккупацию национадьного нарратива.

Споры вокруг названия Vabamu были также связаны с восприятием происходящих со сменой поколений перемен в работе памяти. Музей переосмысдил прошлое и настоящее, чтобы ориентироваться на мододое поколение, горизонт опыта которого радикально отличается от имеющегося у поколения жертв репрессий и восприятие свободы у которого больше индивидуадизировано. Для противников Vabamu сотрудники музея сами представдяли молодое поколение, которое утратило связь с тяжелым прошлым Эстонии и прервало память и солидарность между поколениями. Предпочтение перспективы многих вместо нарратива, повествующего о жертвах и противостоянии было истолковано как упадок этической позиции по отношению к жертвам и тривиализация травмы.

Музей в результате дебатов о названии отказался от радикальной смены названия и остался при названии Музей оккупаций и свободы - Vabamu. Дебаты о понятии «оккупации» показади значимость языкового определения в масштабной борьбе за представление прошлого. Концепция оккупации являлась ядром политического идентитета как посткоммунистической Эстонии, так и других стран Балтии. Понятие оккупации связано с самыми важными элементами в нарративе постсоветской Эстонии. Связь памяти о (советской) оккупации с политикой безопасности в ходе дебатов о Vabamu указывает на одну основную причину резистентности культуры памяти Эстонии - т.н. русскую угрозу, которая ощущается как экзистенциональная угроза, постоянный вызов существованию Эстонского государства. Проведенные ранее исследования показали, что персональная, социальная, культурная и политическая память прочно переплелась в воспоминаниях о XX веке: т.н. национальная история образует прочную основу для семейной истории. Это превращает национальный нарратив в личный. Предоставление угрозы для центральных символов исторической памяти запускает страхи и актуализирует моральную ответственность за сохранение общего прошлого. 